Article

\title{
Classification of Small- and Medium-Sized Enterprises Based on the Level of Industry 4.0 Implementation
}

\author{
Martin Pech $(\mathbb{D}$ and Jaroslav Vrchota *(D) \\ Department of Management, Faculty of Economics, University of South Bohemia in Ceske Budejovice, \\ Studentska 13, 37005 Ceske Budejovice, Czech Republic; mpechac@ef.jcu.cz \\ * Correspondence: vrchota@ef.jcu.cz
}

Received: 22 June 2020; Accepted: 24 July 2020; Published: 27 July 2020

\begin{abstract}
Due to Industry 4.0 technologies, small- and medium-sized enterprises have a great opportunity to increase their competitiveness. However, the question remains as to whether they are truly able to implement such modern technologies faster and carry out digital transformation. The main aim of the paper is to classify small- and medium-sized enterprises into various groups, according to the level of implementation of Industry 4.0, using the Index of Industry 4.0. Based on the results of the cluster analysis, the small and medium enterprises are categorized into four different groups, according to the level of implementation of Industry 4.0. There are top Industry 4.0 technological enterprises, I4 start enterprises, noobs enterprises, and I4 advances enterprises. So far, the largest group consists of the small- and medium-sized enterprises that are just starting out with the introduction of Industry 4.0 technologies, such as IT infrastructure, digitalization (data, cloud, data analysis, and information systems), and sensors. On the other hand, the top I4 technological enterprises group is the least numerous. The analysis carried out comparing the smalland medium-sized enterprises with the large enterprises shows that the SMEs still have a lower level of Industry 4.0 implementation. This confirms the assumption that the large enterprises have greater opportunities to use new technologies and transform them into smart factories. However, this situation may change in the future if new technologies become more accessible, and SMEs are worth investing in Industry 4.0 in terms of the return on investment.
\end{abstract}

Keywords: Industry 4.0; SMEs; technologies; cluster analysis; maturity model; implementation

\section{Introduction}

Industry 4.0 (I4) is understood to be a revolutionary method of production. It brings a new perspective on the synergy of production with modern technologies, the maximum possible output, and the minimum resources used (German Standardization Roadmap Industrie 4.0-Version 3, b.r.). The new industrial revolution is changing the rules of competition, as the business models are completely changing as a result of the digitization of factories and the adoption of the Internet of Things concept [1]. The modern Industry 4.0 concept was originally designed as a national initiative for the development of the German economy in 2011.

Initially, Industry 4.0 technology was only available to large enterprises, due to high capital requirements [2]. However, in many countries, the small- and medium-sized enterprises (SMEs) represent more than $90 \%$ of all the enterprises [3]. Even such enterprises are beginning to introduce modern technologies into production gradually [4]. For this reason, it is necessary to map their situation and the degree of implementation of Industry 4.0 so that the enterprises are able to compare each other and get a closer overview of their position on the market. In relation, it is also necessary 
to better evaluate future steps in implementing Industry 4.0, so that they do not face unnecessary implementation difficulties, such as, by Ingaldi [5] and Turkes [6], the narrow product portfolio of SMEs, which does not guarantee full use of the efficiency of automated and autonomous production systems, the cost of obtaining money, the turbulence of the environment from the micro and macro aspect, lack of knowledge about Industry 4.0, more focus on operation at the costs of developing the company, lack of understanding of the strategic importance of industry 4.0, too few human resources, need for continued education of employees, and lack of standards.

The paper is structured as follows: Section 1 is the introduction; Section 2 offers the theoretical background with a current review of the literature; Section 3 covers the materials and methods, describing the main objectives, methods (cluster analysis), and hypotheses; Section 4 contains the results of the analysis and includes SMEs categorization, comparison with large enterprises, and validation of results; Section 5 offers a discussion focused on the main contrubutions and limitations of the research; and Section 6 is the conclusion, which contains the main results and further research challenges.

\section{Theoretical Background}

Industry 4.0, or the fourth industrial revolution, means the use of digital technology in the manufacturing process to produce higher-quality goods at reduced costs. This process has different names throughout the world, e.g., Industry 4.0 in Germany, New Industrial France in France, the National Network for Manufacturing Innovation in the USA, Society 5.0 in Japan, and Made in China 2025 in China, etc.

In general, Industry 4.0 is consists of several elements for small- and medium-sized enterprises: autonomous robots, horizontal and vertical integration, the aforementioned Internet of Things (IoT), cloud computing, high-volume data, and additive manufacturing [7]. Taking into account the general paradigm shift from mass production to mass customization, there is also a need for configurable automatic technologies such as the robots [8]. Although the role of humans in the vision of a new industrial revolution is still considered irreplaceable, with the advances in data visualization, new technical interactions seem to make robots suitable for integration into the industrial environment [9].

This article understands Industry 4.0 as a revolutionary industrial concept of the production process in manufacturing, focused on new technologies that interconnect machines and equipment with digital data into automatic, intelligent systems. This definition is based on a number of authors [10-17], mainly Schumacher [18,19], who analyzed more than 70 works focused on Industry 4.0; Rainer [20], who examined Industry 4.0 on more than 1000 questionnaires; and Kaltenbach [21], who researched Industry 4.0 on 30 German enterprises.

Advanced manufacturing systems, together with Information and Communication Technologies (ICT) analysis tools in small- and medium-sized enterprises, transform production into a modern form of ICT known as the Internet of Things [22]. ICT is a prerequisite for efficient supply chain management, and it plays a vital role in the ability to integrate suppliers and customers to improve supply chain performance [23].

Internet of Things is a new era of computing that is completely outside the traditional desktops. In the new industrial revolution, RFID (Radio Frequency Identification) technologies should meet the requirements of identifiable objects that are located in a computer network in one form or another and in which ICT is invisibly built into the environment around us [24]. Madakam, Ramaswamy, and Tripathi [25] define Internet of Things as an open and comprehensive network of intelligent objects capable of organizing and sharing information, data, and resources and responding to sudden changes in the environment.

One of the other indispensable elements of Industry 4.0 is the largescale data, Big Data, which is gradually coming from the Smart cities, through large enterprises to SMEs, as mentioned by Dwevedi [26]. Big data refers to large data files with a more diverse and complex structure and related processes of visualization, analysis, and storage [27]. Babiceanu and Seker [28] noticed that data analysis alone is the most important aspect of Big Data, without which sub-aspects such as storage or 
collection would not be of great value, and appropriate data analysis can reveal new information and facilitate timely response to emerging opportunities and threats [29].

The basic building block is Cloud Computing, which is more and more often used by SMEs [30]. Assuming an enterprise has the resources to deal with information on the network, Cloud Computing is an alternative for the enterprises that do not intend to invest in their own Information and Communication Technologies resources [31]. The combination of Big Data and Cloud Computing enables process participants to collaborate from different locations, in real time, to improve productivity and security, and ensure project feasibility [32]. Another element of the Industry 4.0 concept, which is increasingly being introduced by SMEs, is additive manufacturing [33], a technology that is rapidly evolving and integrated into production processes and into our daily lives [34]. Additive manufacturing is defined as a group of processes that create objects arising from the deposition of material on layers [35]). Urhal, Weightman, Diver, and Bartolo [36] also noticed that additive production disrupts the traditional supply chain, as the products are produced closer to the intended place of use at the time of the need.

The modern production concept is complemented by other elements of the holistic system, such as modern enterprise resource planning (ERP) cores, simulation, cyber security, augmented/virtual reality, and 3D printing $[37,38]$. Together, these elements are embedded systems with decentralized control and advanced connectivity that collect and exchange real-time information to identify, track, monitor, and optimize the production process [39]. The importance of connectivity and the continuous flow of information created the new machine-to-machine (M2M) interactions wherin products, machines, and factories are connected and they communicate through the industrial Internet.

Another type of interaction is human-to-machine (H2M), which is necessary, as complex and unstructured assignments to robots and production lines are too complex to be fully automated, while these systems are still predominantly tested [40], and SMEs are afraid of it. With increasing digitization and the availability of industry-based data, many new jobs are emerging [41]. Compared to the SMEs, the large enterprises are able to quickly identify new opportunities [42] brought by new technologies, for example, in the areas of ecology [43], monitoring [44], and project management [45]. These and other factors are a critical success factor for SMEs in the current extremely strong and competitive environment [32]. It is assumed that Industry 4.0 will result in a comprehensive communications network that will bring together factories, suppliers, logistics, resources, customers, etc. Each participant in the process will be able to optimize the configuration in real time, depending on the current requirements and status of other participants [46].

SMEs are not yet convinced of the benefits of the Industry 4.0 concepts. The high investment costs of technology and the question of its return rate are factors that hinder the persuasion of enterprises [47]. The most important technologies for SMEs in Romania are, according to Reference [6], robots, vertical and horizontal system integration, Big Data, the Internet of Things, and Cyber-Security. They investigated that the main barriers of implementation are lack of knowledge about Industry 4.0, operation and cost focus, other strategic priorities, lack of skilled employees, etc. The SMEs have a competitive disadvantage compared to large enterprises in up-to-date information technology and systems, lack of advance manufacturing technologies, lack of strategic management, and lack of standards [48]. A method for deciding on the best factors affecting the implementation of Industry 4.0 in Peruvian SMEs [49] was introduced. Their conclusion is that lack of capital and investment is the most important factor, followed by technology, management vision, and workers' skills. The commitment of management in Pakistan in SMEs plays an important role in accessing and exploiting innovative capabilities [50]. The implementation process, research, development, and innovation management systems in industrial SME are analyzed in a case study [51].

The level of Industry 4.0 implementation and readiness in SMEs can be evaluated by various assessment tools. Hamidi, Aziz, Shuhidan, and Mokhsin [52] created the IMPULS maturity assessment model for SMEs in Malaysia. Twenty Italian SMEs examined Pirola, Chimini, and Pinto [53] to find out digital readiness of SMEs, with respect to Industry 4.0. Ganzarain and Errasti [54] presented an Industry 4.0 maturity model for SMEs which starts with vision, followed by roadmap and appropriate projects 
to achieve transformation of an enterprise business model. Kolla, Minufekr, and Plapper [55] linked lean with Industry 4.0 in an assessment model for SMEs. The strategy, manufacturing and operations, technology, digitalization, and people capability are dimensions of the Industry 4.0 maturity model by Reference [56]. However, most of these models do not categorize enterprises. Another maturity model for SMEs was developed by Reference [57], who used a three-dimensional axis composed of organizational dimensions, toolboxes, and maturity levels based on critical review.

The reviewed literature of various approaches, technologies, barriers, and assessment models (tools) illustrates that implementation of Industry 4.0 technologies in SMEs is a contemporary challenge. For evaluating the levels of implementation of Industry 4.0, it is appropriate to use some tools, e.g., the Vrchota-Pech Industry 4.0 index (VPi4 index) [58]. However, there are still possibilities to improve. For the comparison of SMEs, it is preferable to create special groups of mutually comparable enterprises (categorize SMEs). In our paper, we also analyze the level of implementation of Industry 4.0 in SMEs and, based on these results, create their categorization.

\section{Materials and Methods}

The main aim of the paper was the classifation of small- and medium-sized enterprises into various groups, according to the level of implementation of Industry 4.0. The first partial objective of the paper was to analyze the readiness of the small and medium enterprises for the implementation of Industry 4.0. The second objective (a sub-objective) was to compare the level of Industry 4.0 of smalland medium-sized enterprises to that of large enterprises, through the VPi4 index.

\subsection{Data}

The research sample was compiled on the basis data from the Czech Statistical Office, which states that, in the Czech Republic, there were 175,894 enterprises in the manufacturing industry in 2005 [59].

In February 2018 to May 2019, approximately 2500 randomly selected enterprises were asked through the managers to ensure that the $95 \%$ confidence requirement was met at $5 \%$ error margin and $15 \%$ questionnaire return. For equal representation of these 2500 enterprises, we used stratified random sampling based on the size (about 50\% micro and small enterprises; $50 \%$ medium-sized enterprises) and technological intensity (about $50 \%$ of high-tech and low-tech enterprises) of enterprises. The composition of the sample corresponds to this distribution (Table 1).

Table 1. Characteristics of research sample for cluster analysis.

\begin{tabular}{ccc}
\hline Group & Category of Group & Number (\%) \\
\hline \multirow{3}{*}{ Size } & Micro Enterprises (0-9 Employees) & 16.13 \\
& Small Enterprise (10-49 Employees) & 40.32 \\
& Medium Enterprise (50-249 Employees) & 43.55 \\
\hline \multirow{3}{*}{ Technological Intensity } & High-Tech and Medium High-Tech Intensity (HTI) & 48.92 \\
& of which High-Tech Sector (HTS) & 5.91 \\
& Low-Tech and Medium Low-Tech Intensity (LTI) & 43.01 \\
\cline { 2 - 3 } & of which Low-Tech Sector (LTS) & 51.08 \\
& and Medium Low-Tech Sector (MLTS) & 39.25 \\
& & 11.83 \\
\hline
\end{tabular}

The actual rate of return of the questionnaires was $12.5 \%$, and 314 questionnaires were completed (18 questionnaires were further excluded due to the existence of one year on the market and completeness of the survey). A total of 90 questionnaires were filled in by the large enterprises, not included in the cluster analysis for the purpose of the paper; however, they were used in comparison with the smalland medium-sized enterprises.

The sample of small- and medium-sized enterprises therefore comprises a total of 186 enterprises. The questionnaire focused on the main characteristics of Industry 4.0, and its questions were defined 
in cooperation with the managers in the framework of quality research. The main areas of the questionnaire were 13 variables characterizing the various technologies of Industry 4.0 used by enterprises. Table 1, below, summarizes the characteristics of SMEs in terms of technological demands. Classification of the enterprises by size was based on the number of employees of the enterprise, as defined by the methodology of the European Commission [60].

\subsection{Industry 4.0 Index Methodology}

An Industry 4.0 index (VPi4) was used to determine the level of implementation of Industry 4.0 in the small- and medium-sized enterprises. The VPi4 index was developed based on a survey which asked managers of enterprises if they use different Industry 4.0 technologies and processes. The index is based on exploratory factor analysis which identified 3 factors consisting of 13 variables (technologies) described in Reference [58]. These factors and variables were chosen for classification of small- and medium-sized enterprises into various groups, according to the level of implementation of Industry 4.0.

The answers from the questionnaire survey of a sample of small- and medium-sized enterprises were transformed into VPi4 variables, using factor score (as weights), and the levels of the VPi4 index were further calculated. The connection of the VPi4 and questionnaire is described in a previous study [58], which also explains the procedures for creating VPi4. The index consists of three follow-up levels (the factor scores of variables are reported in brackets):

1. The First Level of VPi4 (Digitization and Human Resources Infrastructure)—skilled people (0.61), collecting data (0.82), data storage in cloud (0.63), and data analysis (0.86).

2. The Second Level of VPi4 (Automation and information system/information technology (IS/IT) Infrastructure)—information technology (IT) infrastructure (0.53), MES and ERP (0.75), linked data M2M (0.58), robots in production (0.54), mobile terminals (0.54), and sensors (0.58).

3. The Third Level of VPi4 (Learning and AI Infrastructure) - learning software (0.44), sharing data with suppliers (0.67), virtual reality (VR), and simulations (0.68).

As the factor analysis provides the factors that do not correlate with each other, three levels of VPi4 were appropriate for the cluster analysis. Principal Component Analysis (PCA) was performed to check the level independence, which is also part of the results of the paper. In general, its aim is to reduce high-dimensional data to a few so-called "principal" dimensions, to reveal structure in the data, and so to facilitate their interpretation (for more, see Reference [61]). Consequently, VPi4 levels are to be used for the division and categorization of the SMEs through cluster analysis. Specifically, factor scores of the enterprises, standardized by $z$-score, are used. The standardization process consists of transforming the variables such that they have mean zero and standard deviation one.

\subsection{K-Means Clustering}

Cluster analysis employs a measure of similarity or dissimilarity for assigning points in space to a cluster [62]. K-means clustering is the most popular unsupervised clustering technique for partitioning a given dataset into a set of $k$-groups (clusters). It is an iterative optimization method based on the initial division of objects into k-clusters. The distribution is based on the determination of the $\mathrm{k}$-centroids that form the center of the clusters. The distance of each object to the centroids is then examined based on the Euclidean distance. The object is then assigned to the nearest centroid. A new centroid is then calculated for each cluster as an $m$-dimensional vector of the average values of each variable. The cycle is then repeated by calculating distances and assigning objects to these clusters. The process is performed as long as the objects are moved between the clusters [63].

The purpose of cluster analysis was to discover a system for categorizing and grouping the enterprises based on correlation obtained by evaluating factor variables. The enterprises with high positive correlation were grouped and separated by negative correlators. Cluster analysis calculations 
were performed by software R, using the following packages: ggplot2 [64], factoextra [65] and cluster [66], rgl [67], scatterplot3d [68], gridExtra [69], and dplyr [70].

K-means algorithm can be summarized as follows [71]:

1. Specify the number of clusters ( $k$ ) based on the Elbow method (graphical form) and Average Silhouette method (Equation (1)). Silhouette coefficient (SC) finds the average distance to the best-fitting cluster, compared to the average distance between a data point, $x \in C_{k}$, and other points of $C_{k}$, for determining cluster system appropriateness [62]:

$$
S C=\frac{1}{N} \sum_{i=1}^{N} \frac{b(x)-a(x)}{\max \{a(x), b(x)\}}
$$

where $x_{i}$ is a data object belonging to the cluster $C_{k}, a(x)$ is cohesion (average distance of $x$ to all other vectors in the same cluster), and $b(x)$ is separation (average distance of $x$ to the vectors in other clusters). A value of +1 indicates a perfect clustering choice, and a value below 0 indicates a bad clustering choice. We try to find the minimum among the clusters.

2. Initialize Cluster Centroids by randomly selecting $k$-objects from the dataset as the initial cluster centers or means.

3. Form $k$-clusters by assigning each object $\left(x_{i}\right)$ to its closest centroid, based on the Euclidean distance (Equation (2)) between the object and the centroid [72]:

$$
W\left(C_{k}\right)=\sum_{x_{i} \in C_{k}}\left(x_{i}-\mu_{k}\right)^{2},
$$

where $x_{i}$ is a data object belonging to the cluster $C_{k}$, and $\mu_{k}$ is the mean value of the objects assigned to the cluster $C_{k}$.

4. Re-compute the centroid of each cluster. For each of the k-clusters, update the cluster centroid by calculating the new mean values of all the data points in the cluster.

5. Repeat Steps 3 and 4, until the cluster assignments stop changing or the maximum number of iterations (usually 10) is reached. Iteratively minimize the total within sum of square (Equation (3)) of the objects to their assigned cluster centers $\left(\mu_{k}\right)$. Total within sum of square is defined as follows [72]:

$$
\sum_{k=1}^{k} W\left(C_{k}\right)=\prod_{k=1}^{k} \sum_{x_{i} \in C_{k}}\left(x_{i}-\mu_{k}\right)^{2},
$$

The smaller the value $\mathrm{W}\left(\mathrm{C}_{\mathrm{k}}\right)$, the better the clustering $\left(C_{k}, x_{i}\right)$. Although, finding an optimal pair $\left(C_{k}, x_{i}\right)$ is quite a computationally intensive task; finding either optimal $S$ or optimal $\mathrm{c}$ is fairly easy.

6. Clusters validation consists of measuring the goodness of clustering results, using one-way Analysis Of Variance (ANOVA test). The ANOVA F-test evaluates if there are any differences between group means of clusters. Further, the Tukey method of "Honest Significant Difference" is performed for multiple pairwise comparisons of the means of clusters in the analysis of variance (for more, see Reference [61]).

\subsection{Statistical Analysis and Hypotheses}

The research results were also tested by a statistical analysis. The aim of this analysis was to compare the results of the Industry 4.0 VPi4 index of the small- and medium-sized enterprises with those of the large enterprises. A comparison was performed at three VPi4 levels, including the overall index:

$\mathrm{H}_{0}$ : The VPi4 index of small- and medium-sized enterprises and VPi4 index of large enterprises are identical populations. 
$\mathrm{H} 1_{\mathrm{A}}$ : The VPi4 index of small- and medium-sized enterprises and VPi4 index of large enterprises are different populations.

Furthermore, the dependence between subjective perception of Industry 4.0 level and VPi4 Index was investigated by using Pearson and Spearman correlation coefficients. The index was expected to correlate, to some extent, with the subjective perception of the situation in the enterprise. The working hypotheses, verified at the $5 \%$ significance level, are as follows:

$\mathrm{H}_{2}$ : There is no dependency between the perception of Industry 4.0 in enterprises and theVPi4 index of small- and medium-sized enterprises.

$\mathrm{H} 2_{\mathrm{A}}$ : There is dependency between the perception of Industry 4.0 in enterprises and the VPi4 index of small- and medium-sized enterprises.

Statistical evaluation of tests was performed by using Statistica 12 and R software.

\section{Results}

This is a summary of the results obtained at various stages of the research. The results are divided into two parts: cluster of SMEs analysis and comparison SMEs index of VPi4 with large enterprises.

\subsection{Cluster Analysis of Small-and Medium-Sized Enterprises}

The aim of the cluster analysis was to categorize and categorize SMEs based on three levels of the Industry 4.0 index (VPi4). First, the procedure of selecting variables (factors) for clustering is summarized, and then the optimal number of clusters is found, using Elbow a Silhouette methods. The next part presents the results of k-means cluster analysis, including the description of the clusters. Finally, the results of the cluster analysis are validated.

\subsubsection{Variables Selection and Principal Component Analysis}

Before performing the cluster analysis, it was necessary to choose the variables to be used in clustering. Based on the results of the questionnaire survey, the VPi4 index was calculated for the SMEs. The index consists of three factors (levels): VPi4 Level 1, VPi4 Level 2, and VPi4 Level 3. These factors should not correlate with each other, so it was advisable to use three levels of the VPi4 index. Principal Component Analysis (PCA) was performed to check the independence of these factors. The results are summarized in Table 2 . All three dimensions have very similar $\%$ of total variance explained.

Table 2. Principal Component Analysis.

\begin{tabular}{ccccc}
\hline Variable $^{*}$ & Eigenvalue & Total Variance $\%$ & Cumulative Eigenvalue & Cumulative \% \\
\hline VPi4 Level 1 & 1.0954 & 36.41 & 1.0954 & 36.51 \\
VPi4 Level 2 & 1.0097 & 33.66 & 2.1051 & 70.17 \\
VPi4 Level 3 & 0.8949 & 29.83 & 3.0000 & 100.00 \\
\hline
\end{tabular}

${ }^{*}$ Note: variables are Industry 4.0 index values (VPi4) at different levels.

\subsubsection{Optimal Number of Clusters Determination}

In this step, the goal is to determine the optimal number of clusters suitable for k-means cluster analysis. It is advisable to use more methods for this purpose, i.e., the Elbow and Silhouette methods in particular (Figure 1). The procedure consists in performing decompositions for different numbers of k-clusters. A value of total within sum of square is calculated for each decomposition (in Elbow method Equation (3)) and Silhouette coefficient (Equation (1)). Using the k-means algorithm, we divide the data sequentially into two to ten clusters and construct the corresponding function of the number of the clusters. In this case, there is a steep bending in four clusters (Figure 1a). In the case of the Silhouette method, the analysis is performed similarly, obtaining the optimal number of clusters based 
on the maximum value of the coefficient (Figure 1b). Both methods choose four clusters as the best solution for k-means clustering.

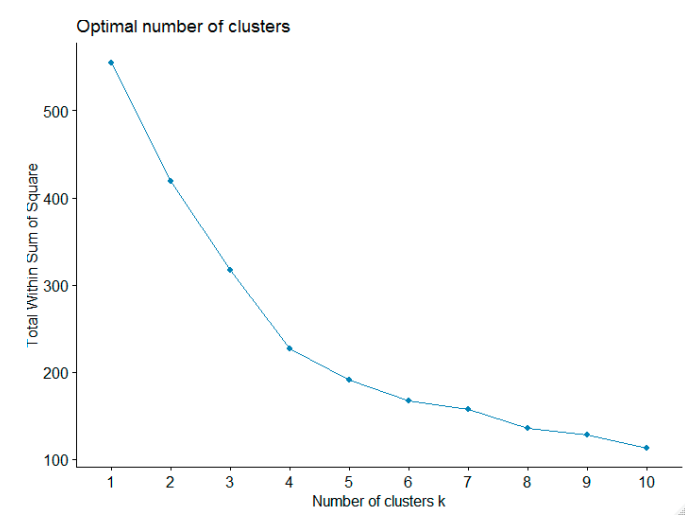

(a)

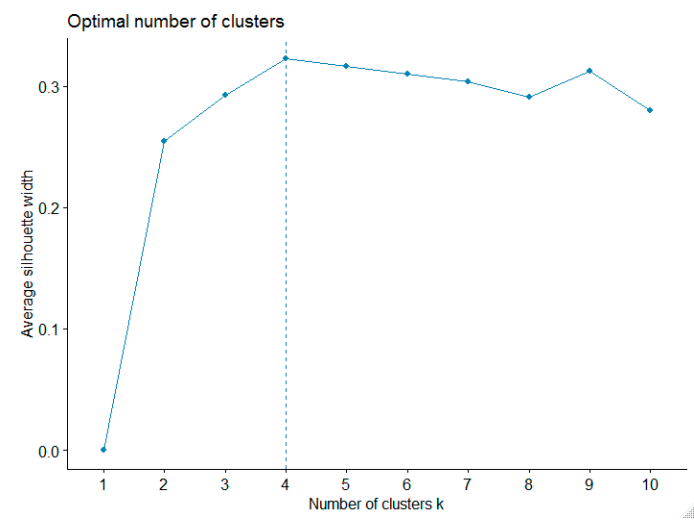

(b)

Figure 1. Optimal number of clusters methods results: (a) Elbow method and (b) Silhouette method.

\subsubsection{Results of Cluster Analysis}

Based on the performed PCA to select the clustering variables and to determine the optimal number of analysis clusters, a k-means cluster analysis was performed. The calculations were performed in software R, using factoextra and cluster packages. The results are summarized in Table 3, which shows that four rather consistent clusters with 32 to 65 elements were created. Table 3 reports the values within sum of squares (WSS), maximum within cluster distances as diameter, average distance within clusters (which should be as small as possible), and separation with minimum distances of a point in the cluster to a point to another cluster reported for each cluster.

Table 3. Results of k-means clustering.

\begin{tabular}{ccccc}
\hline Variable & Cluster $\mathbf{1}$ & Cluster 2 & Cluster 3 & Cluster 4 \\
\hline Within Sum of Squares & 57.6031 & 61.8557 & 73.8122 & 33.4195 \\
Diameter & 3.9006 & 3.7375 & 3.5976 & 2.7862 \\
Average Distance & 1.7915 & 1.4810 & 1.4024 & 1.1872 \\
Separation & 0.2584 & 0.3370 & 0.2584 & 0.3583 \\
Cluster Size & 32 & 49 & 65 & 40 \\
\hline
\end{tabular}

The graphical depiction of the cluster analysis is shown in Figure 2, which shows the results of the cluster analysis in relation to factor variables (VPi4 Level 1, Level 2, and Level 3) in 3D and then in 2D space. It is also evident from Figure $2 b$ that the dimensions of the variables have different directions, confirming their independence. However, it is also evident that there is some overlap in the clusters. This overlap is also explained by the fact that the factor variables are partly complementary and reflect the levels of Industry 4.0. Achieving the second level is conditional by the first level; the achievement of the third level is partly conditional by reaching the first and second levels. 


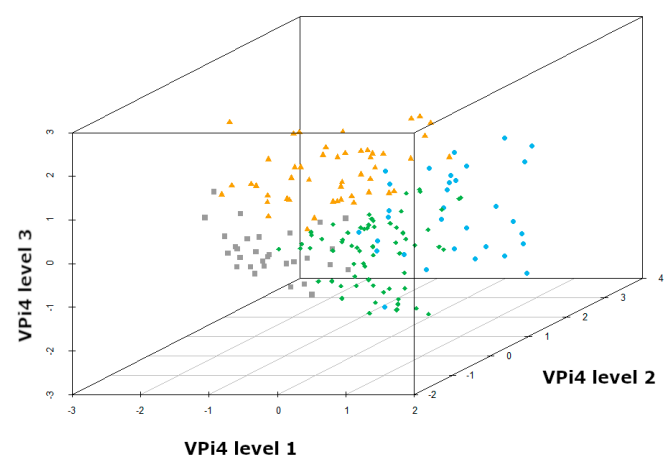

(a)

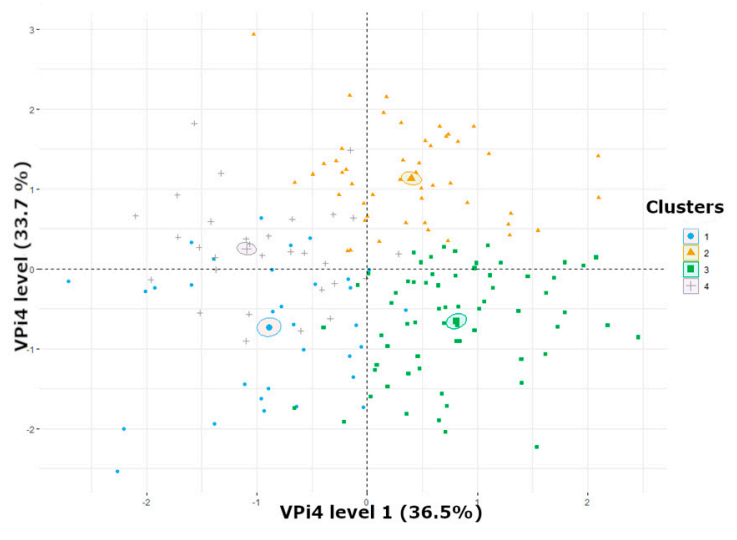

(b)

Figure 2. K-means and PCA analysis results: (a) clusters based on three factors (i.e., F1, F2, and F3) in 3D space; (b) biplot-PCA combined with cluster analysis (relations of the clusters and factors).

Table 4 shows results of $\mathrm{k}$-means clustering according to the centroids average characteristics of the Industry 4.0 levels in individual clusters. Cluster 1 is strongly represented by the first and second levels of the VPi4 index. This means that Cluster 1 contains the enterprises with the highest industry implementation rate of 4.0 on average. Cluster 2 only shows a high rate for Factor 3 , which is a certain extension of the implementation of Industry 4.0 technologies. Cluster 3 achieves positive values only for the first level of the VPi4 index. So far, its average enterprise achieves only a certain initial industry-leading implementation level of 4.0. The latest cluster, Cluster 4, contains the lowest average values at almost all levels. On average, it is an enterprise with a very low implementation rate of Industry 4.0 .

Table 4. Results of k-means clustering-cluster means (centroids).

\begin{tabular}{ccccc}
\hline Factor & Cluster 1 & Cluster 2 & Cluster 3 & Cluster 4 \\
\hline VPi4 Level 1 & 0.6123 & -0.2678 & 0.7175 & -1.3276 \\
VPi4 Level 2 & 1.3700 & -0.0685 & -0.7312 & 0.0931 \\
VPi4 Level 3 & -0.4001 & 1.5000 & -0.2943 & -0.7022 \\
\hline
\end{tabular}

\subsubsection{Comprehensive Description of the Clusters}

The next part describes the characteristics of clusters in details, based on the characteristics of the enterprises that make them up. It is mainly the relation of the clusters to VPi4 index, its levels, the technologies used by the enterprises, the existence of Industry 4.0 strategies, subjective perception of Industry 4.0 levels by the managers, composition in terms of size, and technological demands of the enterprises in the clusters and others. Based on the prevailing tendencies, the clusters are named as follows:

Cluster 1-top I4 technological enterprises;

Cluster 2-advances I4 enterprises;

Cluster 3-I4 starting enterprises;

Cluster 4-I4 noobs enterprises.

First, the characteristics related to the VPi4 index are defined: It is clear from Figure $3 a$ that the clusters differ in the level (0-100\%) achieved by the VPi4 index values. Cluster 4 enterprises ("noobs enterprises") account for more than $80 \%$ of the very low $0-25 \%$ index. On the other hand, Cluster 1 ("top technological enterprises") and Cluster 2 ("advances enterprises") have the largest share of the $50-100 \%$ index. Both of these categories of the enterprises thus achieve a relatively significant index value. Cluster 3 ("start enterprises") contains mainly the enterprises with an index of 25-50\%. 


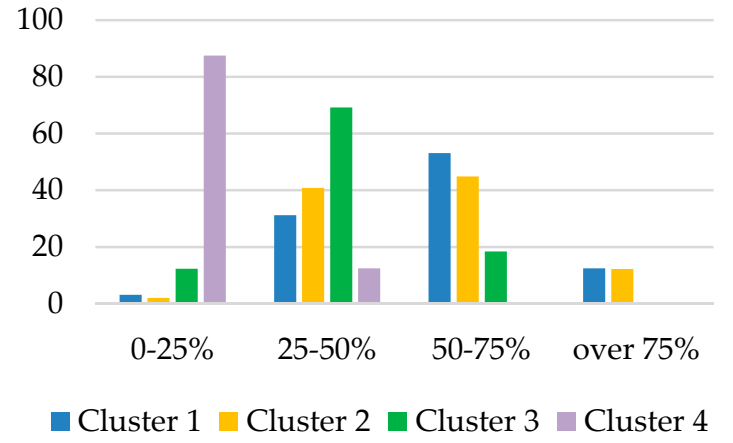

(a)

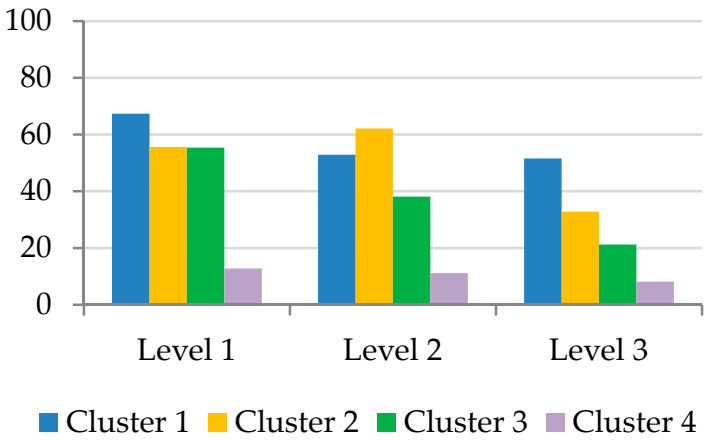

(b)

Figure 3. Characteristics of clusters based on the VPi4 index: (a) VPi4 index results of enterprises (0-25\% minimum, over 75\% maximum of VPi4 index level) and (b) VPi4 index levels 1-3 (Factors 1-3) results.

Figure $3 \mathrm{~b}$ shows a more detailed resolution of each index level. Cluster 4 has low VPi4 index value at all levels; Cluster 3 has low VPi4 index value at the first two levels, in particular; and Clusters 1 and 2 have a decent rating at all the levels of the index. The distinction between Cluster 1 and Cluster 2 is subjected to further analysis with regard to the similarity of the VPi4 index level.

Other criteria in describing the characteristics of the clusters are related to a subjective evaluation of VPi4 level by the managers and the existence of Industry 4 strategy. Figure 4a summarizes the results of the subjective evaluation of Industry 4 level by the managers on a scale of 1 (low) to 5 (high). From the results, it is clear that, even in the case of Cluster 4, the managers perceived the level of Industry 4.0 at most companies at a low level. A relatively large proportion of managers reported their ranking to be low, similarly, in Cluster 3. The enterprises in Clusters 3 and 4 (mostly 80\% of them) have no Industry 4.0 strategy (Figure $4 \mathrm{~b}$ ). The best subjective perception of the implementation of Industry 4.0 was in Clusters 1 and 2. The enterprises in these clusters (approximately 50\% of them) also have an Industry 4.0 strategy. These characteristics divide the clusters into two groups (Figure $4 \mathrm{~b}$ ).

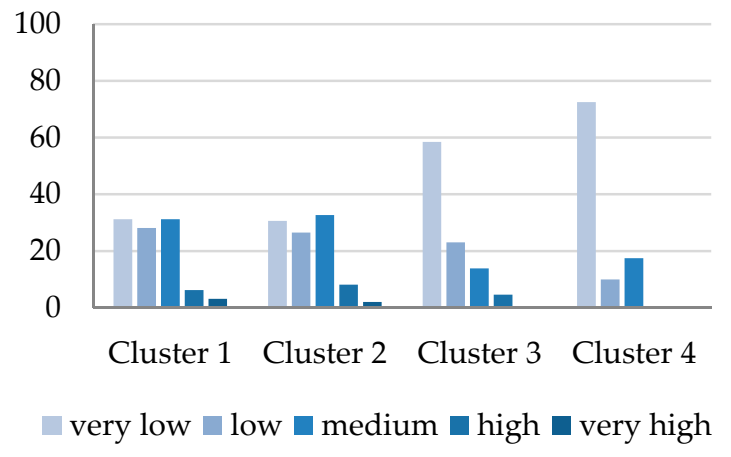

(a)

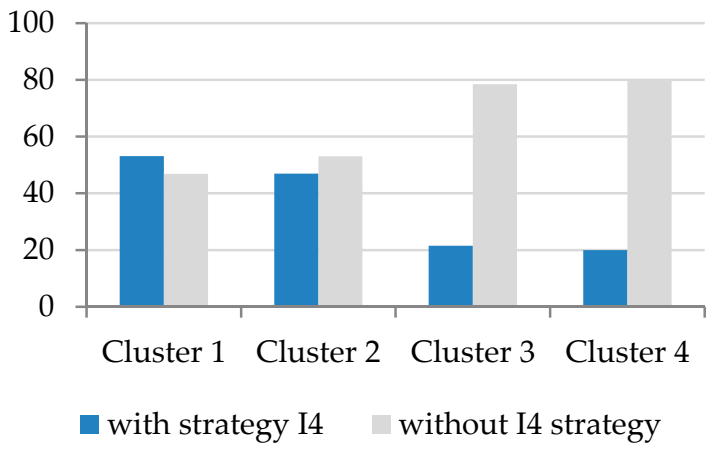

(b)

Figure 4. Characteristics of clusters, based on subjective assessment of Industry 4.0 (I4): (a) subjective assessment of Industry 4.0 implementation by enterprises (very low, low, medium, high, or very high implementation of I4) and (b) clusters according to the existence of I4 strategy in enterprises.

\subsubsection{Description of Each Cluster}

Further, the clusters are described separately for better clarity of the differences in the use of the technologies and characteristics of the enterprises. Following four clusters are described: 
1. Top Industry 4.0 Technological Enterprises (Cluster 1)

There are 32 enterprises in the cluster. In terms of size, these are medium-sized enterprises (40.65\%). Cluster 1 is characterized by $53.13 \%$ enterprises that implement the strategy of Industry 4.0 . Mostly, there are the enterprises $(56.25 \%$ ) with high-tech and medium high-tech intensity (HTI), mostly electro and engineering (53.13\%). These enterprises use a large variety of I4 technologies (Figure 5a). Technological enterprises have a very high value of variables at the first level of the VPi4, such as people, data, cloud, and analysis. These enterprises have a high value of variables as mobile platforms and IT and an average value of sensors and M2M at the second level of the VPi4. At the third level of the VPi4, these enterprises have an average value of VR, sharing data, and learning software. Some enterprises already use nanotechnologies and $3 \mathrm{D}$ printers. In general, the technology is the largest in these enterprises, especially at the first and second levels of the index. Due to this, they are called "I4 top technological enterprises".

2. Industry 4.0 Advances Enterprises (Cluster 2)

The second cluster comprises 49 enterprises, of which $65.31 \%$ are the medium-sized enterprises. A total of $46.94 \%$ of the enterprises in this cluster have an Industry 4.0 strategy. Similar to the first cluster, there are predominantly (65.31\%) high-tech and medium-high intensity (HTI) enterprises in the electro and engineering sector $(63.27 \%)$. The cluster is characterized by the enterprises with a high rating for some technologies (Figure $5 b$ ). These enterprises have average values of variables at first VPi4 level, such as analysis, data, and people. However, most of them still have not using cloud. At the second VPi4 level, they use a high level of IT and IS (ERP and MES). They already introduced some technologies as sharing data and learning software from the third VPi4 level. Some companies use, to a lesser extent, other Industry 4.0 applications, such as nanotechnologies, 3D printers, or auto-vehicles. Overall, enterprises in this cluster use technologies that are supported mainly by IT and infrastructure at the second level of the index. However, some higher-level technologies are used. Due to this, they are called "Advances I4 enterprises".

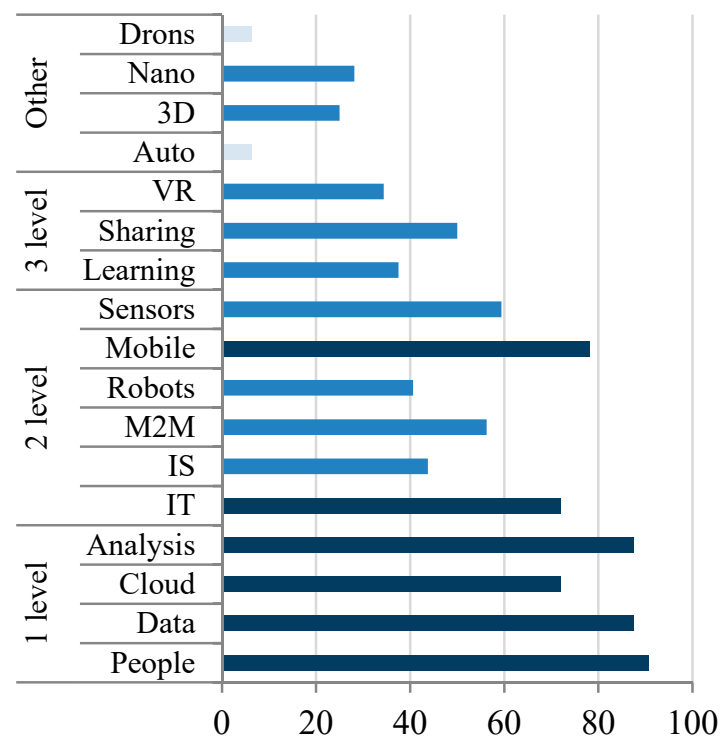

(a)

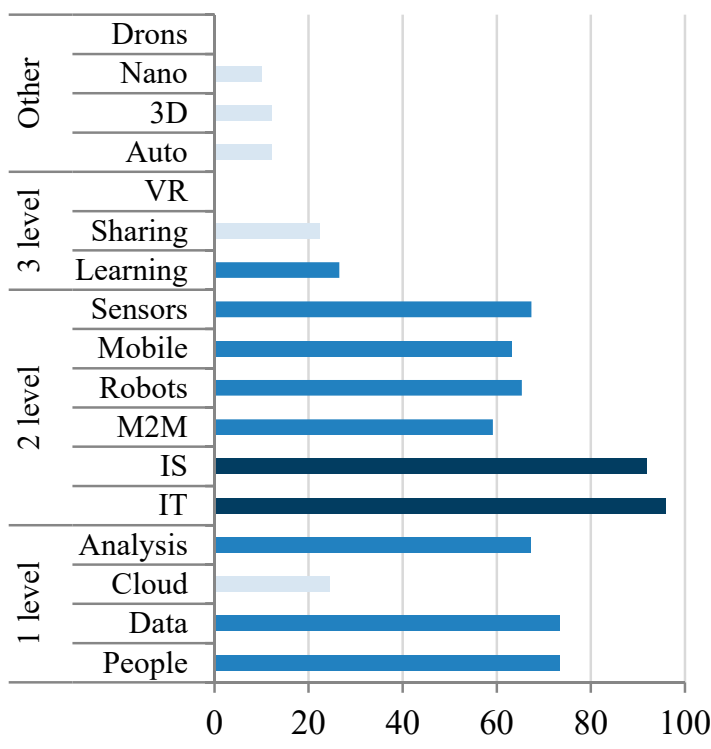

(b)

Figure 5. Clusters' characteristics: (a) Cluster 1-I4 technological enterprises; (b) Cluster 2-I4 advances enterprises. 
3. Iindustry 4.0 Starting Enterprises (Cluster 3)

The third cluster consists of a total of 65 enterprises. The vast majority of these enterprises is small $(47.69 \%)$. However, only $21.54 \%$ of them developed an Industry 4.0 strategy. In terms of technological intensity, there are mostly the (61.54\%) enterprises with low-tech and medium low-tech intensity (LTI), predominantly the electro and engineering enterprises $(38.47 \%)$. This cluster includes enterprises which have started implementing Industry 4.0 technologies (Figure 6a). These enterprises have a very high value of variables at the first level of VPi4, such as in people, data, and analysis and average value of cloud. They already have IT infrastructure and, at the average level, have IS and sensors. These enterprises did not use robots, M2M, or mobile technologies. The third level value of VPi4 is very low, as compared to other applications of Industry 4.0. In general, these enterprises are characterized by the introduction of technology only at the first level of the index. Due to this, they are called "I4 starting enterprises".

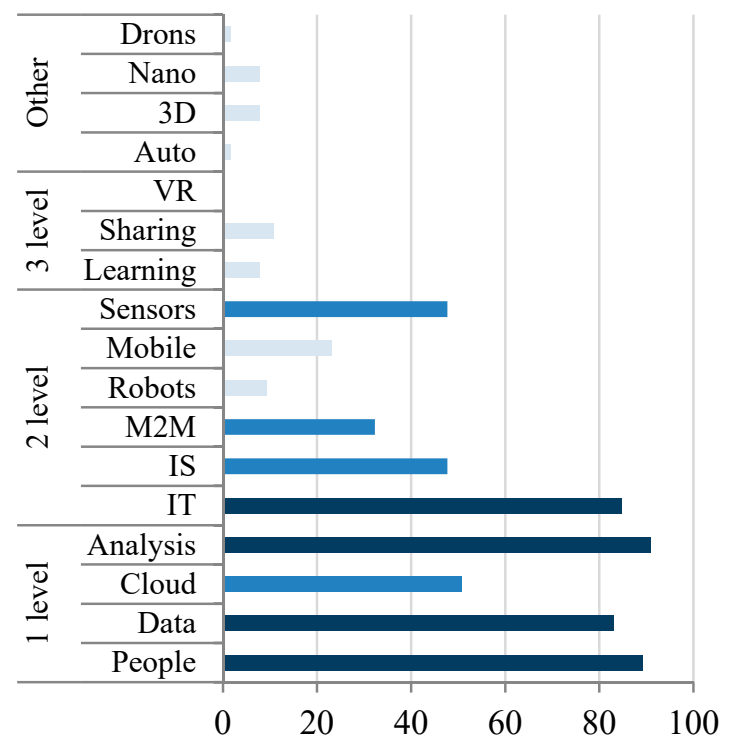

(a)

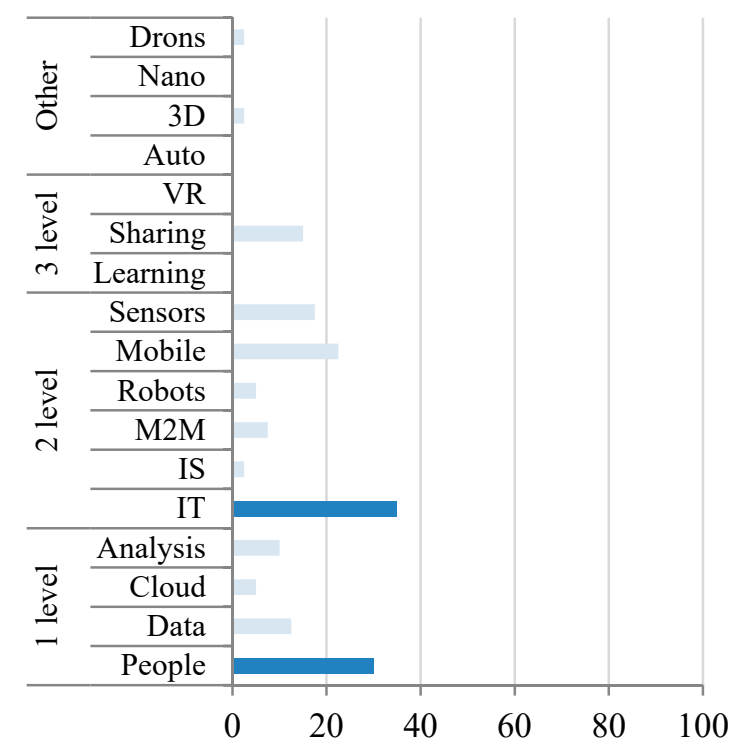

(b)

Figure 6. Clusters characteristics: (a) Cluster 3-I4 starting enterprises; (b) Cluster 4-I4 noobs enterprises.

4. Industry 4.0 Noobs Enterprises (Cluster 4)

The fourth cluster consists of 40 enterprises of a very low level of technology. Of the total, $40 \%$ are the small enterprises, and 30\% are the micro-enterprises. Only 20\% of them have an Industry 4.0 strategy. These are mostly (60\%) the enterprises with low-tech and medium low-tech intensity (LTI). Almost 32.5\% of them produce the products for domestic market, so that they probably do not require high technology use. These enterprises have very low values of almost all technologies of Industry 4.0 (Figure 6b). They are usually without new technologies or they are using only basic IT infrastructure. Second or third level of VPi4 and other applications of Industry 4.0 are not presented yet. Due to this, they are called "I4 noobs".

\subsubsection{Validation of Cluster Analysis}

The validity of the cluster analysis results was verified by one-way ANOVA F-tests for each clustered factor (VPi4 Level 1, Level 2, and Level 3). The results of this analysis should verify whether there are statistically significant differences between the clusters. In the one-way ANOVA test, we used a $p$-value significance level 0.05 , but some of the cluster means are different. If the $p$-value for all four variables is greater than 0.05 (labeled by ${ }^{* \prime \prime}$ in Table 5), excluding them from the analysis should be 
considered. The results of the factor ANOVA are shown in Table 5. The results show that, for all variables, there are some differences among the clusters.

Table 5. Results of ANOVA test.

\begin{tabular}{|c|c|c|c|c|}
\hline Clusters & Sum Sq & Mean Sq & F-Value & $\operatorname{Pr}(>F)^{1}$ \\
\hline VPi4 Level 1 & 144.45 & 48.15 & 110.6 & $2 \times 10^{-16 * * *}$ \\
\hline VPi4 Level 2 & 86.98 & 28.994 & 79.33 & $2 \times 10^{-16 * * *}$ \\
\hline VPi4 Level 3 & 109.84 & 36.61 & 77.91 & $2 \times 10^{-16 * * * 1}$ \\
\hline
\end{tabular}

However, the ANOVA results cannot be interpreted unambiguously, as it is not clear which pairs of clusters are different. It is advisable to use the Tukey Honest Significant Difference (HSD) test (for multiple pairwise comparison) to find out if there is a statistically significant difference between the means of certain cluster pairs. The results of this analysis are summarized in Table 6. In most cases, the differences between the clusters are statistically significant. However, there were no differences between Cluster 3 and Cluster 1 for VPi4 Level 1; there were no the differences between Clusters 4 and 2 for VPi4 level 2, and three differences for VPi4 level 3. This means that there are some overlaps between the clusters, especially for VPi4 Level 3 factor variables. Such lack of differences in the clusters may partly be due to the fact that all factors are considered follow-up levels of the VPi4 index. In the case of the small- and medium-sized enterprises, it is typical that most of these enterprises do not reach the high third level of the index. Therefore, their values are rather lower, and this causes the similarity of the clusters. Therefore, the differences in clusters of VPi4 Level 3 are not so significant. However, such conclusion should not diminish the significance of the cluster analysis and the fact that the clusters are different. The differences are also reported by Table 3 (see within sum of squares, diameter, average distance, separation, etc.).

Table 6. Results of the Tukey Honest Significant Difference (HSD) test.

\begin{tabular}{|c|c|c|c|c|c|}
\hline $\begin{array}{l}\text { Dependent } \\
\text { Variable }\end{array}$ & $\begin{array}{c}\text { Clusters } \\
\text { Comparison }\end{array}$ & $\begin{array}{c}\text { Mean } \\
\text { Difference }\end{array}$ & Lower Bound ${ }^{2}$ & Upper Bound ${ }^{2}$ & $p$-Value ${ }^{1}$ \\
\hline \multirow{6}{*}{ VPi4 Level 1} & $2-1$ & -0.9677 & -1.3565 & -0.5788 & $2 \times 10^{-5 * * *}$ \\
\hline & $3-1$ & 0.1157 & -0.2538 & 0.4851 & 0.848 \\
\hline & $4-1$ & -2.1330 & -2.5388 & -1.7272 & $2 \times 10^{-5 * * *}$ \\
\hline & $3-2$ & -1.0833 & -1.4070 & -0.7597 & $2 \times 10^{-5 * * *}$ \\
\hline & $4-2$ & 1.1654 & 0.8008 & 1.5299 & $2 \times 10^{-5 * * *}$ \\
\hline & $4-3$ & -2.2487 & -2.5925 & -1.9049 & $2 \times 10^{-5 * * *}$ \\
\hline \multirow{6}{*}{ VPi4 Level 2} & $2-1$ & -1.4048 & -1.7611 & -1.0486 & $2 \times 10^{-4 * * *}$ \\
\hline & $3-1$ & -2.0085 & -2.3470 & -1.6700 & $2 \times 10^{-4 * * *}$ \\
\hline & $4-1$ & -1.2576 & -1.6294 & -0.8858 & $2 \times 10^{-4 * * *}$ \\
\hline & $3-2$ & 0.6036 & 0.3071 & 0.9002 & $2 \times 10^{-4 * * *}$ \\
\hline & $4-2$ & -0.1473 & -0.4813 & 0.1868 & 0.662 \\
\hline & $4-3$ & 0.7509 & 0.4359 & 1.0659 & $2 \times 10^{-4 * * *}$ \\
\hline \multirow{6}{*}{ VPi4 Level 3} & $2-1$ & 1.6700 & 1.2660 & 2.0740 & $0.001 * * *$ \\
\hline & $3-1$ & 0.1087 & -0.2751 & 0.4926 & 0.8824 \\
\hline & $4-1$ & -0.3104 & -0.7320 & 0.1111 & 0.2261 \\
\hline & $3-2$ & 1.5613 & 1.2250 & 1.8976 & $0.001 * * *$ \\
\hline & $4-2$ & 1.9805 & 1.6017 & 2.3592 & $0.001^{* * *}$ \\
\hline & $4-3$ & -0.4191 & -0.7763 & -0.0619 & $0.0142 *$ \\
\hline
\end{tabular}

${ }^{1}$ Significant codes: ${ }^{* * * \prime} 0.001,{ }^{* * \prime} 0.01$, and ${ }^{\prime * \prime} 0.05 .{ }^{2}$ The lower and the upper end point of the confidence interval at $95 \%$ (default).

Another method of cluster analysis validation is related to the abovementioned methods, to determining the optimal number of clusters, the Silhouette and Elbow method. The methods were used to determine the parameters of the cluster analysis in order to achieve the most accurate results. However, it should be noted that the average value of Silhouette coefficient is only 0.32 . The reason for 
this is the overlap of the factor VPi4 Level 3. Another way to verify the validity of a cluster analysis is, for example, the Dunn index, calculated as the ratio of minimum separation/maximum diameter [73,74], 0.06623, in the paper. The higher the Dunn index value, the better the clustering is.

\subsection{Comparison SMEs Index of VPi4 with Large Enterprises}

Subsequently, the large enterprises (90 enterprises) and the SMEs were compared in terms of VPi4\%. After the Mann-Whitney-Wilcox test was used to test the statistics, at a significance level of 0.05 , the differences between the two groups of the enterprises were tested in the overall VPi4\% index and also at the different levels (Levels $1-3)$. In all cases, the null hypothesis $\left(\mathrm{H}_{0}\right)$ on the agreement of both groups) was rejected in favor of the alternative hypothesis $\left(\mathrm{H} 1_{\mathrm{A}}\right.$, claiming that the large enterprises reach a higher VPi4\% level). The results in Table 7 show that the VPi4 index of small- and medium-sized enterprises (SMEs) and VPi4 index of large enterprises (LEs) is different populations.

Table 7. Industry 4.0 index (VPi4) distribution, using Mann-Whitney-Wilcox test.

\begin{tabular}{ccccc}
\hline Variable & Median Les $^{\mathbf{1}}$ & Median SMEs $^{\mathbf{1}}$ & $\mathbf{Z}$ & $\boldsymbol{p}$-Value \\
\hline VPi4\% Total & 57.212 & 39.070 & 6.061 & 0.000 \\
VPi4\% Level 1 & 64.741 & 50.512 & 5.002 & 0.000 \\
VPi4\% Level 2 & 62.855 & 42.451 & 6.512 & 0.000 \\
VPi4\% Level 3 & 43.654 & 25.198 & 5.667 & 0.000 \\
\hline
\end{tabular}

1 Note: differences between VPi4 index median of large enterprises (LEs) and small- and medium-sized enterprises (SMEs).

The normalization of the data of both variables was verified by the Shapiro-Wilk tests, with the $p$-value of VPi $\%=0.002$ and the perception of Industry 4.0 by the enterprises $p$-value $=0.000$, assuming the normality of the data, as also shown by both histograms. After that, the VPi4\% and the subjective perception rate of Industry 4.0 were compared by using both Pearson and Spearman correlation coefficients. The Table 8 below shows the values of the tested statistics for both samples. It is apparent from $p$-values close to zero that, in both large and small enterprises, VPi4\% correlates with the subjective perception of enterprises. In both cases, the correlation rate is very similar. Results show that there is dependency between the perception of Industry 4.0 in the enterprises and the VPi4 index of the smalland medium-sized enterprises. The $\mathrm{H} 2_{0}$ hypothesis was rejected in favor of $\mathrm{H} 2_{\mathrm{A}}\left(\right.$ Hypothesis $2_{\mathrm{A}}$ ) at a significance level of 0.05 .

Table 8. Relation to subjective perception of Industry 4.0, based on Pearson and Spearman coefficients.

\begin{tabular}{|c|c|c|c|c|c|c|c|}
\hline \multicolumn{2}{|c|}{-} & \multicolumn{3}{|c|}{ Pearson } & \multicolumn{3}{|c|}{ Sperman } \\
\hline Research $^{1}$ & Variables & Perception & VPi4 & $p$-Value & Perception & VPi4 & $p$-Value \\
\hline \multirow{2}{*}{ LEs } & Perception & 1.000 & 0.384 & \multirow{2}{*}{0.000} & 1.000 & 0.383 & \multirow{2}{*}{0.000} \\
\hline & Index VPi4 & 0.384 & 1.000 & & 0.383 & 1.000 & \\
\hline \multirow{2}{*}{ SMEs } & Perception & 1.000 & 0.385 & \multirow{2}{*}{0.000} & 1.000 & 0.387 & \multirow{2}{*}{0.000} \\
\hline & Index VPi4 & 0.385 & 1.000 & & 0.387 & 1.000 & \\
\hline
\end{tabular}

${ }^{1}$ Note: Research was conducted between large enterprises (LEs) and small- and medium-sized enterprises (SMEs).

Overall, the results show that these small- and medium-sized enterprise groups differ statistically significantly from large enterprises in their implementation and use of Industry 4.0 technologies.

\section{Discussion}

Here we present a discussion of our major findings and results. This section offers contributions and identifies limitations of the research. 


\subsection{General Discussion of Results}

The cluster approach has gained extensive acceptance among academics and policymakers as an effective development strategy both for an industry and society [75], as evidenced by a number of studies focusing on innovation in SMEs [76-79] or technology SMEs [80] or their performance [81-83]. In this paper, according to statistical models, SMEs were divided into four clusters. This number is very common for this type of enterprises, as evidenced by the studies by Refereces $[84,85]$; or a very similar number is used, as with References [86,87]. An appropriate study of Industry 4.0 clusters and levels is also supported by the Austrian study on the implementation of Industry 4.0 [88], where deployed technologies also determine the level of implementation.

As confirmed by the results, Cluster 1 enterprises have the highest level, and they are characterized by a high level of Industry 4.0 deployment and have all the technology levels that they use successfully. These conclusions are also supported by a Romanian study on barriers to deployment [6], when the importance of technology for Industry 4.0 is emphasized by Reference [89], an article by a Finnish author on production systems. Brozzi [90] used self-assessment tools for Industry 4.0 readiness in SMEs with current and expected levels of digitalization. This author distinguished an average score of the current four-level groups of enterprises: traditional craftsman (very low score), digital newcomer (low score), ambitious (high score), and digital champion (very high score). These categories are almost similar to the categories in our research.

The contributions were in agreement with the research of Woods [84], who confirmed differences in Industry 4.0 levels among SMEs and large enterprises, while supporting the claim of Dubrova [87] that small businesses often do not have high technology; this can also be due to their difficulty in accessing free capital and the associated IT spending, as reported by Statista [91], and they start to increase significantly year-on-year (5\% increase between 2017 and 2018; 15\% increase between 2018 and 2019). Data for the largest expenditure areas around the world from 2006 to 2021 [92] show that SMEs increased investment into business services $(7.1 \%)$ and software $(6.9 \%)$. By contrast, only $54 \%$ of small- and medium-sized businesses store data in the cloud, compared to $92 \%$ of large businesses [93], where the research from Cluster 2 is lagging behind most. According to Computer Economics [94], differences in robotic process automation adoption rate in 2019 among small- and medium-sized enterprises $(9 \%)$ and large enterprises $(24 \%)$ are very high. These differences are more pronounced for the rate of investment in the robotic process, where large enterprises covar about $49 \%$, while small-sized ones have only $14 \%$, and middle-sized enterprises about $17 \%$ investment.

As the results showed, technological enterprises have very high value of variables at the first level VPi4. The importance of people is also emphasized by Nickel et al. [95], data by Chumnumporn et al. [96], cloud by Erasmus et al. [97] and analysis by Choy et al. [98]. These enterprises have high value of variables as mobile platforms and IT; average value of sensors and M2M at second-level VPi4, which is not yet widely used by SMEs [99]. At the third level of VPi4, these enterprises have an average value of VR, sharing data, and learning software. Some enterprises already use nanotechnologies and 3D printers, which is contrary to the study of Pallas [100], which claims that these technologies attribute predominantly to large companies; Gaudin [101] makes the same claim, but stresses their importance for sustainable development.

\subsection{Theoretical and Practional Implications}

Based on the VPi4 index, SMEs can be divided into four groups. The practical benefits include the possibility of comparing the company with others, both based on the classic VPi4 index and in terms of classification into one of four groups of clusters. Managers of SMEs can compare their own enterprises with those of competitors and understand which technologies may be suitable for further deployment in relation to the competitive advantage. The enterprise can better analyze the current weaknesses and strengths of technical factors. In practice, it is very difficult to determine the level of technology in an enterprise, especially in SMEs, which have limited capacities and funding opportunities. Thanks to 
our model, managers will get a better overview of the current situation, as they can use our model in planning and strategy development for the future.

Developed classification of enterprises extends the possibilities of VPi4 index especially for SMEs. SMEs are specific in terms of I4 technology implementation. The proposed categorization of enterprises into four groups also offers easy comparison of enterprises. Due to the limited capital and the necessity to choose only one of many possible technologies, the implementation process of I4 in SMEs is not usually gradual by individual index levels (from first to second level and above). Small- and medium-sized enterprises often have different needs when introducing new technologies. Their preferences are evidenced by clustering.

The results point out which Industry 4.0 technologies are most often used by small- and medium-sized enterprises. The results confirmed that these are mainly technologies at the first level, i.e., analysis, collecting data, cloud storage (and for them having skilled people). With the exception of I4 technological enterprises group and partly I4 advances enterprises group, small- and medium-sized enterprises do not use a higher level of VPi4 index technologies (virtual reality, data sharing, and learning software) or special applications, such as 3D printing, drones, or nanotechnology. From this perspective, the paper extends knowledge about the use of technology in SMEs.

Another theoretical contribution is confirmation of the hypothesis of different approaches to technology between SMEs and large enterprises. The differences between SMEs and large enterprises show that large enterprises have a higher level of Industry 4.0 implementation. On the other hand, SMEs have the advantage of implementing new technologies due to greater flexibility; more involved, empowered employees; less bureaucracy and coordination due to the usually leaner organizational structure; and the ability to produce customized products and close relationship with customers. These benefits should be used by SMEs to increase value-added services and tailored manufacturing processes.

\subsection{Limitations}

However, some study limitations should be acknowledged. In the paper we used for cluster analysis the VPi4 index [58], which has some limitations. First, the VPi4 index does not include some Industry 4.0 technologies (block chain, laser technology, RFID, drones, 3D printers, track-n-trace, nanotechnology, autonomous vehicles, etc.). Second, the VPi4 index is based on the results of a questionnaire survey. Some limitations of this kind of method should therefore be considered. Third, the VPi4 index was not verified by confirmatory factor analysis and structural model equation method. This problem will be resolved in the future, after the third wave of questionnaire survey research on Industry 4.0. Currently, the results and structure of the VPi4 index are confirmed by relation to subjective perception of the level of Industry 4.0 by the enterprises and re-test in second wave of the research [58]. Fourth, the VPi4 index is based on the research in the Czech Republic and can be limited to the specifics of this Country. Our study was conducted in the same country, so it should not be a problem. Another limit may be the use of only factors in the field of technology, without taking into account, for example, financial data, which also prove to be very important in terms of sustainable development [102].

The questionnaire research on small- and medium-sized enterprises had a lower rate of return than we expected. Therefore, the margin of error (5.86\%) was higher than 5\% at $95 \%$ confidence level. The error, therefore, slightly exceeded the planned level. However, we assume that this will not affect the results. Moreover, the sample size was not representative in the case of proportionality of the Czech Republic enterprise population. Rather, the research sample was created in regard to the size of the enterprises and technological demands of the industry.

Other limitations include problems related to k-cluster analysis methods. The main issues of this method are handling empty clusters (special situation) and outliers (centroids may not be representative for all cases). K-means is not suitable for all types of data. It cannot handle non-globular clusters 
or data without a specific center [71]. Another issue could be selecting the wrong number of initial clusters. This can be solved by Elbow, Silhouette, or other methods.

The results of the factory analysis validation based on the Tukey HSD test shows similarities between clusters especially at the third level of the VPi4 index. Similarly, this overlap is also confirmed by the average Silhouette coefficient and the lower Dunn index. This clustering issue is based on the fact that most small- and medium-sized enterprises do not reach the highest level of the VPi4 index. Similarity is therefore in low index values. However, in spite of this problem, the different categories of clusters are different from each other. With the increasing level of implementation of Industry 4.0 in SMEs, this issue will be eliminated in the future, and the differences between the clusters will become more noticeable. Hovewer, the relation between Industry 4.0 implementation and the size of an enterprise is still significant [103].

\section{Conclusions}

To conclude this paper, we summarize the results of the research. The paper deals with the analysis of the level of Industry 4.0 implementation in SMEs. Based on cluster analysis, we developed a categorization of the enterprises which consists of four groups, namely top I4 technological enterprises, advances I4 enterprises, I4 starting enterprises, and I4 noobs enterprises. The largest group is formed by SMEs, which are just-introduced Industry 4.0 technologies. Depending on their classification, enterprises differ in the use of preferred technologies. Generally, SMEs are more used technologies that can be found at lower levels of the VPi4 index (data collection, analysis, Cloud, IS, IT, and mobile platforms). At the same time, SMEs with a higher level of implementation of Industry 4.0 reported enough skilled human resources.

The research examined hypotheses about the differences between SMEs and large enterprises in the implementation of Industry 4.0. Results of comparisons show that SMEs have, so far, a lower level of Industry 4.0 implementation. This confirms the assumption that large enterprises have greater opportunities to use new technologies and transform them into smart factories. However, this situation may change in the future if new technologies become more accessible (for example, using leasing financing) and more appropriate for investment of SMEs.

As part of future research, we plan to conduct a deeper analysis of the implementation of Industry 4.0 in SMEs, focusing on the main barriers. Case studies on specific enterprises will be appropriate. These case studies could explain why SMEs are not yet implementing Industry 4.0 to a greater extent. We plan to show the procedure of how to rank the implementation steps or technologies in a single enterprise. It may be interesting to compare the current and required (or expected) level of Industry 4.0 in SMEs. Other challenges for future research include developing a methodology (step-by-step roadmap) to implement Industry 4.0 in enterprises. SMEs often do not have much information on how they can turn their business into a digital form; however, in the current situation (pandemic of coronavirus), they are forced to use home office and reduced working hours. New Industry 4.0 technologies can help them with this current challenge.

Author Contributions: Conceptualization, M.P. and J.V.; data curation, M.P. and J.V.; formal analysis, M.P. and J.V.; funding acquisition, M.P. and J.V.; investigation, M.P. and J.V.; methodology, M.P. and J.V.; project administration, M.P. and J.V.; resources, M.P. and J.V.; software M.P. and J.V.; supervision, M.P.; validation, M.P. and J.V.; visualization, M.P.; writing—original draft, M.P.; writing—review and editing, M.P. and J.V. All authors have read and agreed to the published version of the manuscript.

Funding: This research was funded by "EF-150-GAJU 047/2019/S".

Acknowledgments: The authors thank the enterprises taking part in the research.

Conflicts of Interest: The authors declare no conflict of interest. 


\section{References}

1. Dalenogare, L.S.; Benitez, G.B.; Ayala, N.F.; Frank, A.G. The expected contribution of Industry 4.0 technologies for industrial performance. Int. J. Prod. Econ. 2018, 204, 383-394. [CrossRef]

2. Novotná, M.; Volek, T. Efficiency of production factors in the EU. Cent. Eur. J. Reg. Dev. Tour. 2018, 10, 147-168.

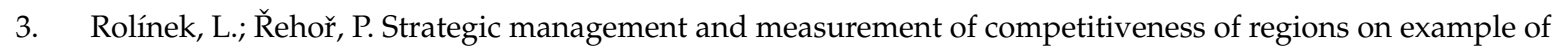
countries EU. J. Cent. Eur. Agric. 2008, 9, 17-22.

4. Sahi, G.K.; Gupta, M.C.; Cheng, T.C.E. The effects of strategic orientation on operational ambidexterity: A study of indian SMEs in the industry 4.0 era. Int. J. Prod. Econ. 2020, 220, 107395. [CrossRef]

5. Ingaldi, M.; Ulewicz, R. Problems with the implementation of industry 4.0 in enterprises from the SME sector. Sustainability 2020, 12, 217. [CrossRef]

6. Turkes, M.C.; Oncioiu, I.; Aslam, H.D.; Marin-Pantelescu, A.; Topor, D.I.; Capusneanu, S. Drivers and barriers in using industry 4.0: A perspective of SMEs in Romania. Processes 2019, 7, 153. [CrossRef]

7. Ahmi, A.; Elbardan, H.; Raja Mohd Ali, R.H. Bibliometric analysis of published literature on industry 4.0. In Proceedings of the 2019 International Conference on Electronics, Information, and Communication (ICEIC), Auckland, New Zealand, 22-25 January 2019; IEEE: Auckland, New Zealand, 2019; pp. 1-6.

8. Pedersen, M.R.; Nalpantidis, L.; Andersen, R.S.; Schou, C.; Bøgh, S.; Krüger, V.; Madsen, O. Robot skills for manufacturing: From concept to industrial deployment. Robot. Comput. Integr. Manuf. 2016, 37, $282-291$. [CrossRef]

9. Maly, I.; Sedlacek, D.; Leitao, P. Augmented reality experiments with industrial robot in industry 4.0 environment. In Proceedings of the 2016 IEEE 14th International Conference on Industrial Informatics (INDIN), Poitiers, France, 19-21 July 2016; IEEE: Poitiers, France, 2016; pp. 176-181.

10. Zambon, I.; Cecchini, M.; Egidi, G.; Saporito, M.G.; Colantoni, A. Revolution 4.0: Industry vs. agriculture in a future development for SMEs. Processes 2019, 7, 36. [CrossRef]

11. Lin, B.; Wu, W.; Song, M. Industry 4.0: Driving factors and impacts on firm's performance: An empirical study on China's manufacturing industry. Ann. Oper. Res. 2019. [CrossRef]

12. Kabugo, J.C.; Jämsä-Jounela, S.-L.; Schiemann, R.; Binder, C. Industry 4.0 based process data analytics platform: A waste-to-energy plant case study. Int. J. Electr. Power Energy Syst. 2020, 115, 105508. [CrossRef]

13. Madsen, D.Ø. The emergence and rise of industry 4.0 viewed through the Lens of management fashion theory. Adm. Sci. 2019, 9, 71. [CrossRef]

14. Hahn, G.J. Industry 4.0: A supply chain innovation perspective. Int. J. Prod. Res. 2020, 58, $1425-1441$. [CrossRef]

15. Galati, F.; Bigliardi, B. Industry 4.0: Emerging themes and future research avenues using a text mining approach. Comput. Ind. 2019, 109, 100-113. [CrossRef]

16. Jena, M.C.; Mishra, S.K.; Moharana, H.S. Application of Industry 4.0 to enhance sustainable manufacturing. Environ. Prog. Sustain. Energy 2020, 39, 13360. [CrossRef]

17. Shukla, A.K.; Nath, R.; Muhuri, P.K.; Lohani, Q.M.D. Energy efficient multi-objective scheduling of tasks with interval type-2 fuzzy timing constraints in an Industry 4.0 ecosystem. Eng. Appl. Artif. Intell. 2020, 87, 103257. [CrossRef]

18. Schumacher, A.; Erol, S.; Sihn, W. A Maturity model for assessing Industry 4.0 readiness and maturity of manufacturing enterprises. Procedia Cirp 2016, 52, 161-166. [CrossRef]

19. Schumacher, A.; Nemeth, T.; Sihn, W. Roadmapping towards industrial digitalization based on an Industry 4.0 maturity model for manufacturing enterprises. Procedia Cirp 2019, 79, 409-414. [CrossRef]

20. Rainer, A.; Hall, T. Key success factors for implementing software process improvement: A maturity-based analysis. J. Syst. Softw. 2002, 62, 71-84. [CrossRef]

21. Kaltenbach, F.; Marber, P.; Gosemann, C.; Bolts, T.; Kuhn, A. Smart services maturity level in Germany. In Proceedings of the 2018 IEEE International Conference on Engineering, Technology and Innovation (ICE/ITMC), Stuttgart, Germany, 17-20 June 2018; IEEE: Stuttgart, Germany, 2018; pp. 1-7.

22. Hamzeh, R.; Zhong, R.; Xu, X.W. A survey study on Industry 4.0 for New Zealand manufacturing. Procedia Manuf. 2018, 26, 49-57. [CrossRef]

23. Ben-Daya, M.; Hassini, E.; Bahroun, Z. Internet of things and supply chain management: A literature review. Int. J. Prod. Res. 2019, 57, 4719-4742. [CrossRef] 
24. Gubbi, J.; Buyya, R.; Marusic, S.; Palaniswami, M. Internet of Things (IoT): A vision, architectural elements, and future directions. Future Gener. Comput. Syst. 2017, 29, 1645-1660. [CrossRef]

25. Madakam, S.; Ramaswamy, R.; Tripathi, S. Internet of Things (IoT): A literature review. J. Comput. Commun. 2015, 3, 164-173. [CrossRef]

26. Dwevedi, R.; Krishna, V.; Kumar, A. Environment and big data: Role in smart cities of India. Resources 2018, 7, 64. [CrossRef]

27. Sagiroglu, S.; Sinanc, D. Big data: A review. In Proceedings of the 2013 International Conference on Collaboration Technologies and Systems (CTS), San Diego, CA, USA, 20-24 May 2013; IEEE: San Diego, CA, USA, 2013; pp. 42-47.

28. Babiceanu, R.F.; Seker, R. Big Data and virtualization for manufacturing cyber-physical systems: A survey of the current status and future outlook. Comput. Ind. 2016, 81, 128-137. [CrossRef]

29. Sivarajah, U.; Kamal, M.M.; Irani, Z.; Weerakkody, V. Critical analysis of big data challenges and analytical methods. J. Bus. Res. 2017, 70, 263-286. [CrossRef]

30. Abubakr, M.; Abbas, A.T.; Tomaz, I.; Soliman, M.S.; Luqman, M.; Hegab, H. Sustainable and smart manufacturing: An integrated approach. Sustainability 2020, 12, 2280. [CrossRef]

31. Branco, T.; de Sá-Soares, F.; Rivero, A.L. Key issues for the successful adoption of cloud computing. Procedia Comput. Sci. 2017, 121, 115-122. [CrossRef]

32. Maskuriy, R.; Selamat, A.; Ali, K.N.; Maresova, P.; Krejcar, O. Industry 4.0 for the construction industry-how ready is the industry? Appl. Sci. 2019, 9, 2819. [CrossRef]

33. Bambach, M.; Sviridov, A.; Weisheit, A.; Schleifenbaum, J.H. Case studies on local reinforcement of sheet metal components by laser additive manufacturing. Metals 2017, 7, 113. [CrossRef]

34. Bandyopadhyay, A.; Susmita Bose, S. (Eds.) Additive Manufacturing, 2nd ed; CRC Press: Boca Raton, FL, USA, 2019; ISBN 978-1-138-60925-9.

35. Gibson, I.; Rosen, D.; Stucker, B. Additive Manufacturing Technologies; Springer: New York, NY, USA, 2015; ISBN 978-1-4939-2112-6.

36. Urhal, P.; Weightman, A.; Diver, C.; Bartolo, P. Robot assisted additive manufacturing: A review. Robot. Comput. Integr. Manuf. 2019, 59, 335-345. [CrossRef]

37. Venkatraman, S.; Fahd, K. Challenges and success factors of ERP systems in Australian SMEs. Systems 2016, 4, 20. [CrossRef]

38. Alcácer, V.; Cruz-Machado, V. Scanning the Industry 4.0: A literature review on technologies for manufacturing systems. Eng. Sci. Technol. Int. J. 2019, 22, 899-919.

39. Rojko, A. Industry 4.0 concept: Background and overview. Int. J. Interact. Mob. Technol. 2017, 11, 77-90. [CrossRef]

40. Elfekey, H.; Bastawrous, H.A.; Okamoto, S. A Touch sensing technique using the effects of extremely low frequency fields on the human body. Sensors 2016, 16, 2049. [CrossRef]

41. Stojanova, H.; Lietavcova, B.; Vrdoljak Raguž, I. The Dependence of unemployment of the senior workforce upon explanatory variables in the European Union in the context of Industry 4.0. Soc. Sci. 2019, 8, 29. [CrossRef]

42. Koilo, V. Evidence of the environmental kuznets curve: Unleashing the opportunity of Industry 4.0 in emerging economies. J. Risk Financ. Manag. 2019, 12, 122. [CrossRef]

43. Tsai, W.-H. Green Production planning and control for the textile industry by using mathematical programming and Industry 4.0 techniques. Energies 2018, 11, 2072. [CrossRef]

44. Ageyeva, T.; Horváth, S.; Kovács, J.G. In-mold sensors for injection molding: On the way to Industry 4.0. Sensors 2019, 19, 3551. [CrossRef]

45. Vrchota, J.; Ǩehoř, P. Project management and innovation in the manufacturing industry in Czech Republic. Procedia Comput. Sci. 2019, 164, 457-462. [CrossRef]

46. Maresova, P.; Soukal, I.; Svobodova, L.; Hedvicakova, M.; Javanmardi, E.; Selamat, A.; Krejcar, O. Consequences of Industry 4.0 in business and economics. Economies 2018, 6, 46. [CrossRef]

47. Sevinc, A.; Gur, S.; Eren, T. Analysis of the difficulties of SMEs in industry 4.0 applications by analytical hierarchy process and analytical network process. Processes 2018, 6, 264. [CrossRef]

48. Kleindienst, M.; Ramsauer, C. SMEs and industry 4.0-introducing a KPI based procedure model to identify focus areas in manufacturing industry. Athens J. Bus. Econ. 2016, 2, 109-122. [CrossRef] 
49. Huang, C.J.; Chicoma, E.D.T.; Huang, Y.H. Evaluating the factors that are affecting the implementation of industry 4.0 technologies in manufacturing MSMEs, the case of Peru. Processes 2019, 7, 161. [CrossRef]

50. Imran, M.; Salisu, I.; Aslam, H.D.; Iqbal, J.; Hameed, I. Resource and information access for SME sustainability in the era of IR 4.0: The mediating and moderating roles of innovation capability and management commitment. Processes 2019, 7, 211. [CrossRef]

51. Cerezo-Narviez, A.; Garcia-Jurado, D.; Gonzalez-Cruz, M.C.; Pastor-Fernandez, A.; Otero-Mateo, M.; Ballesteros-Perez, P. Standardizing innovation management: An opportunity for SMEs in the aerospace industry. Processes 2019, 7, 282. [CrossRef]

52. Hamidi, S.R.; Aziz, A.A.; Shuhidan, S.M.; Mokhsin, M. SMEs Maturity Model Assessment of IR4.0 Digital Transformation; Springer: Singapore, 2018; Volume 739, ISBN 9789811086113, ISSN 21945357.

53. Pirola, F.; Cimini, C.; Pinto, R. Digital readiness assessment of Italian SMEs: A case-study research. J. Manuf. Technol. Manag. 2019. [CrossRef]

54. Ganzarain, J.; Errasti, N. Three stage maturity model in SME's towards industry 4.0. J. Ind. Eng. Manag. 2016, 9, 1119-1128. [CrossRef]

55. Kolla, S.; Minufekr, M.; Plapper, P. Deriving Essential Components of Lean and Industry 4.0 Assessment Model for Manufacturing SMEs.; Butala, P., Govekar, E., Vrabic, R., Eds.; Elsevier Bv: Amsterdam, The Netherlands, 2019; Volume 81, pp. 753-758.

56. Chonsawat, N.; Sopadang, A. The Development of the Maturity Model to Evaluate the Smart SMEs 4.0 Readiness; IEOM Society: Southfield, MI, USA, 2019; Volume 2019, pp. 354-363.

57. Mittal, S.; Khan, M.A.; Romero, D.; Wuest, T. A critical review of smart manufacturing \& Industry 4.0 maturity models: Implications for small and medium-sized enterprises (SMEs). J. Manuf. Syst. 2018, 49, 194-214.

58. Vrchota, J.; Pech, M. Readiness of enterprises in Czech Republic to implement industry 4.0: Index of industry 4.0. Appl. Sci. 2019, 9, 5405. [CrossRef]

59. Czech Statistical Office. Available online: https://www.czso.cz/documents/10180/23169600/ht_odvetvi.pdf/cb 4dc782-a3e0-43a4-8d96-99b8d1f14cca (accessed on 20 February 2020).

60. European Commission. Recommendation of 6 May 2003 Concerning the Definition of Micro, Small and Medium-Sized Enterprises (Text with EEA Relevance) (Notified under Document Number C (2003) 1422); The Publications Office of the European Union: Luxembourg, 2003.

61. Little, T. The Oxford Handbook of Quantitative Methods, Vol.2: Statistical Analysis; Oxford University Press: New York, NY, USA, 2013.

62. King, R.S. Cluster Analysis and Data Mining: An Introduction; Mercury Learning and Information: Boston, MA, USA, 2015.

63. Rezankova, H. Shluková Analýza Dat (Cluster Data Analysis); Professional Publishing: Praha, Czech Republic, 2007.

64. Wickham, H. Ggplot2: Elegant Graphics for Data Analysis; Springer: New York, NY, USA, 2016.

65. Lemenkova, P. K-Means clustering in R libraries \{cluster\} and \{factoextra\} for Grouping Oceanographic Data. Int. J. Inform. Appl. Math. 2019, 2, 1-26.

66. Maechler, M.; Rousseeuw, P.; Struyf, A.; Hubert, M.; Hornik, K. Cluster: Cluster Analysis Basics and Extensions. R Package Version 2.1.0. Available online: https:/cran.r-project.org/web/packages/cluster/ (accessed on 20 February 2020).

67. Adler, D.; Murdoch, D. Rgl: 3D Visualization Using OpenGL. Available online: https://www.researchgate.n et/publication/318392813_Rgl_3D_Visualization_Using_OpenGL (accessed on 1 February 2020).

68. Ligges, U.; Mächler, M. Scatterplot3d-An R package for visualizing multivariate data. J. Stat. Softw. $2003,8$. [CrossRef]

69. Babtiste, A. GridExtra: Miscellaneous Functions for "Grid" Graphics. R Package Version 2.3.2017. Available online: https://CRAN.R-project.org/package=gridExtra (accessed on 20 February 2020).

70. Wickham, H.; François, R.; Henry, L.; Müller, K. Dplyr: A Grammar of Data Manipulation. R Package Version 0.7.6. Available online: https://CRAN.R-project.org/package=dplyr (accessed on 20 February 2020).

71. Tan, P.N.; Steinbach, M.; Karpatne, A.; Kumar, V. Introduction to Data Mining, 2nd ed.; Pearson: Harlow, UK, 2019.

72. Hennig, C.; Meila, M.; Murtagh, F.; Rocci, R. Handbook of Cluster Analysis; CRC Press: New York, NY, USA, 2016.

73. Halkidi, M.; Batistakis, Y.; Vazirgiannis, M. Cluster validity methods: Part I. ACM Sigmod Rec. 2002, 31, 40-45. [CrossRef] 
74. Halkidi, M.; Batistakis, Y.; Vazirgiannis, M. Cluster validity methods: Part II. ACM Sigmod Rec. 2002, 31, $19-27$. [CrossRef]

75. Rahman, S.M.T.; Kabir, A. Potential cluster regions for manufacturing small and medium enterprises in khulna city of bangladesh: A spatial examination. Int. J. Recent Technol. Eng. 2019, 8, 980-986.

76. Rodríguez, A.J.G.; Barón, N.J.; Martínez, J.M.G. Validity of dynamic capabilities in the operation based on new sustainability narratives on nature tourism SMEs and clusters. Sustainability 2020, 12, 1004. [CrossRef]

77. de Oliveira, L.S.; Soares Echeveste, M.E.; Cortimiglia, M.N.; Gularte, A.C. Open innovation in regional innovation systems: Assessment of critical success factors for implementation in SMEs. J. Knowl. Econ. 2019, 10, 1597-1619. [CrossRef]

78. Nestle, V.; Täube, F.A.; Heidenreich, S.; Bogers, M. Establishing open innovation culture in cluster initiatives: The role of trust and information asymmetry. Technol. Forecast. Soc. Chang. 2019, 146, 563-572. [CrossRef]

79. Bahena-Álvarez, I.L.; Cordón-Pozo, E.; Delgado-Cruz, A. Social entrepreneurship in the conduct of responsible innovation: Analysis cluster in Mexican SMEs. Sustainability 2019, 11, 3714. [CrossRef]

80. Pelletier, C.; Cloutier, L.M. Conceptualising digital transformation in SMEs: An ecosystemic perspective. J. Small Bus. Enterp. Dev. 2019, 26, 855-876. [CrossRef]

81. Jami Pour, M.; Asarian, M. Strategic orientations, knowledge management (KM) and business performance: An exploratory study in SMEs using clustering analysis. Kybernetes 2019, 48, 1942-1964. [CrossRef]

82. Cicea, C.; Popa, I.; Marinescu, C.; Ștefan, S.C. Determinants of SMEs' performance: Evidence from European countries. Econ. Res. Ekon. Istraz. 2019, 32, 1602-1620. [CrossRef]

83. Dubravska, M.; Sira, E. The analysis of the factors influencing the international trade of the slovak republic. In Proceedings of the 2nd Global Conference on Business, Economics, Management and Tourism, Prague, Czech Republic, 30-31 October 2014; Iacob, A.I., Ed.; Elsevier: Amsterdam, The Netherlands, 2015; Volume 23, pp. 1210-1216.

84. Woods, J.; Galbraith, B.; Hewitt-Dundas, N. Network centrality and open innovation: A social network analysis of an SME manufacturing cluster. IEEE Trans. Eng. Manag. 2019, 1-14. [CrossRef]

85. Viloria, A.; Lezama, O.B.P. Improvements for determining the number of clusters in k-means for innovation databases in SMEs. Procedia Comput. Sci. 2019, 151, 1201-1206. [CrossRef]

86. Kiefer, C.P.; Carrillo-Hermosilla, J.; Del Río, P. Building a taxonomy of eco-innovation types in firms. A quantitative perspective. Resour. Conserv. Recycl. 2019, 145, 339-348. [CrossRef]

87. Dubrova, T.A.; Ermolina, A.A.; Esenin, M.A. Innovative activities of SMEs in Russia: Constraints and growth factors. Int. J. Econ. Bus. Adm. 2019, 7, 26-40.

88. Pessl, E.; Sorko, S.R.; Mayer, B. Roadmap industry 4.0-Implementation guideline for enterprises. Int. J. Sci. Technol. Soc. 2020, 5, 1728-1743. [CrossRef]

89. Fox, S. Moveable production systems for sustainable development and trade: Limitations, opportunities and barriers. Sustainability 2019, 11, 5154. [CrossRef]

90. Brozzi, R.; D'Amico, R.D.; Pasetti Monizza, G.; Marcher, C.; Riedl, M.; Matt, D. Design of Self-Assessment Tools to Measure Industry 4.0 Readiness. A Methodological Approach for Craftsmanship SMEs; Springer: New York, NY, USA, 2018; Volume 540, ISBN 9783030016135, ISSN 18684238.

91. Statista Worldwide Semiannual Small and Medium Business Spending Guide. Available online: https://www.statista.com/statistics/760799/worldwide-small-medium-business-it-spending/ (accessed on 15 December 2019).

92. IDC Worldwide Semiannual Small and Medium Business Spending Guide. Available online: https: //www.statista.com/statistics/800684/worldwide-small-medium-business-it-spending-growth/ (accessed on 2 January 2020).

93. Statista In-depth: Industry 4.0. Available online: https://www.statista.com/study/66974/in-depth-industry-40/ (accessed on 12 December 2019).

94. Computer Economics Robotic Process Automation Adoption Trends and Customer Experience. Available online: https://www.statista.com/statistics/1017027/worldwide-robotic-process-automation-adoption-inve stment-rates-organization-size/ (accessed on 19 December 2019).

95. Nickel, P.; Bärenz, P.; Radandt, S.; Wichtl, M.; Kaufmann, U.; Monica, L.; Bischoff, H.-J.; Nellutla, M. Human-system interaction design requirements to improve machinery and systems safety. Adv. Intell. Syst. Comput. 2020, 969, 3-13. 
96. Chumnumporn, K.; Jeenanunta, C.; Komolavanij, S.; Saenluang, N.; Onsri, K.; Fairat, K.; Itthidechakhachon, K. The Impact of IT knowledge capability and big data and analytics on firm's industry 4.0 capability. Proceedings 2020, 39, 22. [CrossRef]

97. Erasmus, J.; Grefen, P.; Vanderfeesten, I.; Traganos, K. Smart hybrid manufacturing control using cloud computing and the internet-of-things. Machines 2018, 6, 62. [CrossRef]

98. Choy, M.; Park, G. Sustaining innovative success: A case study on consumer-centric innovation in the ICT industry. Sustainability 2016, 8, 986. [CrossRef]

99. Lara, E.; Aguilar, L.; Sanchez, M.A.; García, J.A. Lightweight authentication protocol for M2M communications of resource-constrained devices in industrial internet of things. Sensors 2020, 20, 501. [CrossRef] [PubMed]

100. Pallas, G.; Peijnenburg, W.J.G.M.; Guinée, J.B.; Heijungs, R.; Vijver, M.G. Green and clean: Reviewing the justification of claims for nanomaterials from a sustainability point of view. Sustainability 2018, 10, 689. [CrossRef]

101. Gaudin, V. The growing interest in development of innovative optical aptasensors for the detection of antimicrobial residues in food products. Biosensors 2020, 10, 21. [CrossRef] [PubMed]

102. Kliestik, T.; Misankova, M.; Valaskova, K.; Svabova, L. Bankruptcy prevention: New effort to reflect on legal and social changes. Sci. Eng. Ethics 2018, 24, 791-803. [CrossRef] [PubMed]

103. Vrchota, J.; Volek, T.; Novotná, M. Factors Introducing Industry 4.0 to SMES. Soc. Sci. 2019, 8, 130. [CrossRef]

(C) 2020 by the authors. Licensee MDPI, Basel, Switzerland. This article is an open access article distributed under the terms and conditions of the Creative Commons Attribution (CC BY) license (http://creativecommons.org/licenses/by/4.0/). 